\title{
DETERMINATION OF INTRAPRENEURSHIP LEVELS OF BANKING EMPLOYEES: BALIKESIR PROVINCE EXAMPLE
}

\section{DOI: 10.17261/Pressacademia.2018.917 \\ PAP- V.7-2018(70)-p.362-366}

Bayram Alamur ${ }^{1}$, Gulten Eren Gumustekin², Ferhat Topbas ${ }^{3}$, Ismail Atabay ${ }^{4}$

${ }^{1}$ Balikesir University, Balikesir, Turkey.

bayramalamur@balikesir.edu.tr, ORCID: 0000-0002-1364-5604

${ }^{2}$ Canakkale Onsekiz Mart University, Canakkale, Turkey.

ggumustekin@comu.edu.tr, ORCID: 0000-0003-0561-1989

${ }^{3}$ Izmir Demokrasi University, Izmir, Turkey.

ferhat.topbas@idu.edu.tr, ORCID: 0000-0002-7576-4668

${ }^{4}$ Balikesir University, Balikesir, Turkey.

atabay@balikesir.edu.tr, ORCID: 0000-0001-8979-5548

To cite this document: Alamur, B., Gumustekin, G. E., Topbas, F., Atabay, I., (2018). Determination of intrapreneurship levels of banking employees: Balikesir provience example. PressAcademia Procedia (PAP), V.7, p.362-366.

Permemant link to this document:http://doi.org/10.17261/Pressacademia.2018.917

Copyright: Published by PressAcademia and limited licenced re-use rights only.

\section{ABSTRACT}

Purpose- While entrepreneurship is a concept that indicates itself in the process of bringing an organization to the stage, intrapreneurship can take place within an existing organization. In the literature, intrapreneurship is defined as taking risks and innovating to make their organizations more competitive and better although it is not on job descriptions.Due to the benefits it provides, organizations are trying to transform intrapreneurship to the culture and organizations want to employ intrapreneurship-oriented employees. Although having different dimensions; innovation, proactiveness, risk taking and autonomy take place in studies. This study aimed to determine the levels of intrapreneurship of the banking sector employees in the service sector, where competition is intense. In this highly competetive environment, banks are trying to differentiate from competitors and gain advantage.

Methodology- The application of the study was made on the employees of national bank branches operating in Balıkesir province by face-to-face survey method. In the questionnaire, a scale consisting of 21 expressions and 4 dimensions developed by Durmaz (2011) using different studies were used in order to measure intrapreneurship. The data obtained from the questionnaire were subjected to statistic alanalysis and the results were interpreted.

Findings- In this study, intrapreneurship levels of banking employees and intrapreneurship status of according to various demographic variables was determined. In our study, banking employees intrapreneurship average was founded 3.71. It has been observed that the level of intrapreneurship of male employees is higher than that of female employees. Employees between the ages of 41 and 45 were found to have higher intrapreneurship scores than others.

Conclusion- As a result of the study, it is concluded that banking employees have high intrapreneurship score and has reached the highest average level of innovation within the dimensions of intrapreneurship. While the topic of intrapreneurship is particularly important for the service sector and similar studies are suggested in other areas.

Keywords: Intrapreneurship, service sector, banking employees.

JEL Codes: D23, G20, L26

\section{BANKA ÇALIŞANLARININ IÇ GIRişiMCILIK DÜZEYLERININ TESPITi: BALIKESIR ILi ÖRNEĞ}

\section{ÖZET}

Amaç- Girişimcilik bir örgütü meydana getirme süreci içerisinde kendisini gösteren bir kavramken, iç girişimcilik var olan bir örgüt içerisinde meydana gelebilmektedir. Literatürde iç girişimcilik, çalışanların, örgütlerini daha rekabetçi ve daha iyi bir duruma getirebilmek için görev tanımlarında bulunmamasına karşın risk almaları ve yenilik üretmeleri olarak tanımlanmaktadır. Yapılan çalışmalarda iç girişimcilik, sağladığı faydalar sebebiyle örgüt yönetimince kültüre dönüştürülmeye çalışımakta ve örgütler iç girişimcilik eğilimli çalışanları istihdam etmek istemektedir. Farklı boyutlandırmaları bulunmakla birlikte ağırlıklı olarak yenilikçilik, proaktiflik, risk alma ve özerklik boyutları çalışmalarda yer edinmektedir.Bu çalışma hizmet sektöründe yer alan ve rekabetin yoğun yaşandığı bankacılık sektörü çalışanlarının iç girişimcilik düzeylerini tespit etmeyi amaçlamıştır. Bankalar bu yoğun rekabet içerisinde yaptıkları yenilik ile rakiplerinden farklılaşmaya ve avantaj sağlamaya çalışmaktadırlar.

Yöntem- Çalışmanın uygulaması Balıkesir ilinde faaliyet gösteren ulusal banka şubelerinin çalışanları üzerinde ve yüz yüze anket yöntemi ile yapılmıştır. Ankette iç girişimciliğin ölçülmesi için farklı araştırmacıların çalışmalarından yararlanılarak Durmaz (2011) tarafından geliştirilen 21 ifade ve 4 boyuttan oluşan ölçek kullanılmıştır. Anket çalışmasından elde edilen veriler istatistiksel analizlere tabi tutulmuş ve sonuçlar yorumlanmıştır. Bulgular- Çalışmada bankacılık çalışanlarnın iç girişmcilik seviyeleri ve çeşitli demografik değişkenlere göre iç girişimcilik durumları tespit edilmiştir. Araştırmamızda örneklem dahilindeki bankacıların iç girişimcilik ortalamaların 3,71 olarak tespit edilmiştir. Erkek çalışanların girişmcilik düzeylerinin kadın çalışanlara göre daha yüksek olduğu gözlemlenmiştir. 41 ile 45 yaş aralığındaki çalışanların diğerlerine göre daha yüksek girişimcilik skoruna sahip oldukları gözlemlenmiştir.

Sonuç- Çalışma sonucunda bankacılık çalışanlarının yüksek iç girişimcilik skoruna sahip oldukları, iç girişimcilik boyutları içerisinde yenilikçilik boyutunun en yüksek ortalamaya sahip olduğu sonucuna ulaşılmıştır. İç girişimcilik konusu özellikle hizmet sektörü için önemli olmakla birlikte başka alanlarda da benzer çalışmaların yapılması önerilmektedir.

Anahtar Kelimeler: İç girişimcilik, hizmet sektörü, banka çalışanları.

JEL Kodları: D23, G20, L26 


\section{GíRiş}

Hızlı değişimlerin belirsizlik ortamında gerçekleştiği günümüzde iç girişimcilik rekabet avantajı açısından önemli bir yere sahiptir. İ̧ girişimcilik, son yıllarda araştırmacıların yoğun ilgisini çeken bir konu olarak karşımıza çıkmaktadır. İç girişimcilik ismi genel kabul görmüş olmakla birlikte, değişik araştırmacılar iç girişimcilik isminden farklı olarak kurumsal girişimcilik, şirket girişimciliği, girişim yönetimi, yeni girişim ve iç şirket girişimciliği gibi isimlendirmeleri de kullanmışlardır(Güler E. B., 2012). İ̧̧ girişimci kelimesi ilk olarak Pinchot (1985) tarafından kullanılmıştır ve yazar iç girişimciyi, bir iş fikrini uygulama sorumluluğunu kurum içinde üstlenen kişi olarak tanımlamıştır. Hill, $M$. E. (2003) ise iç girişimciyi bir işletme içinde bir fikri karlı bir nihai ürüne, risk alma ve yenilik yoluyla dönüştürme sorumluluğunu üstlenen kişi olarak tanımlamıştır. İ̧ girişimciliği; Antoncic ve Hisrich (2001) kurulu bir örgüt içerisinde, yeni girişim yaratmak, Ferreira (2001) örgütteki tüm çalışanların işbirliği ve etkileşimini destekleyen bir süreç, Zahra (1991) mevcut bir örgüt içerisinde, karlılı̆ı ve işletmenin rekabet gücünü arttırmak ve stratejik yenilenmeyi gerçekleştirebilmek için, yeni iş yaratma süreci olarak tanımlamışlardır.

İç girişimcilik tek bir tanıma ve tek tip boyutlandırmalara sahip değildir. Bununla birlikte iç girişimcilik için yazında yer edinmiş dörtlü bir boyutlandırmadan söz edilebilecektir. Bu alt boyutlar; yenilikçilik, risk alma, özerklik ve proaktifliktir. Yenilikçilik; mevcut kaynakları, yeni yaklaşım ve yöntemler geliştirerek artırmak velveya verimli kılmak, bu yönde ürün ya da hizmetleri oluştururken teknolojiye ve ürün bilgisine katkıda bulunmak olarak, Proaktiflik; değişen çevresel koşullarda, uygun çözümleri ve eylemleri önceden öngörebilme ve hazırlıkı olma durumu olarak, Özerklik; bireyi ve grupları sıkan, boğucu örgütsel engellerden kurtulup bağımsız biçimde hareket etme yeteneği ve son olarak Risk alma; iç girişimci bireyin, yenilik süreci içinde üstlendiği riskler olarak tanımlanmaktadır.

Yerli ve yabancı yazın tarandığında iç girişimcilik konusunun; kültür, girişimcilik, iş tatmini, işletme performansı, örgütsel zeka, liderlik, bilgi yönetimi, örgütsel bürokrasi, örgütsel öğrenme, örgütsel performans, inovasyon, örgütsel değişim, bireysel değişim, çalışan performansı, finansal performans, psikolojik güçlendirme algısı gibi konularla birlikte ele alındığı görülmüştür. Yazın taramasında araştırmacılarca iç girişimciliğin; işletme performansını (Augusto ve Caldeirinha, 2012), bireysel ve organizasyonel kararları etkilediği(Parker, 2011), iç girişimci karakteri yoğun olan organizasyonların diğerlerine göre daha fazla büyüme kapasitesine sahip olduğu(Monnavarian ve Ashena, 2009), yeni üretim yöntem ve süreçleri geliştirme konularında işletmeleri desteklediği(Antoncic ve Hisrisch, 2001), çalışanların memnuniyetini artırıp iş gücü devir oranını düşürdüğü(Kaya ve Arkan, 2005), iç girişimcilik yoluyla oluşan rekabet avantajının değişime hızlı tepki verebilme ve örgütsel öğrenme gibi avantajları işletmelere sağladığı (Heinonen ve Korvela, 2003), işletmelerde performans artışı sağladığı (Ağca ve Yörük, 2006), işletmelere esneklik ve canlılık kazandıran bir fonksiyon olduğu(Thornberry, 2001) ve örgütte karlıı̆ğa, stratejik yenilenmeye, yeniliğe ve bilgi kazanımına geçmeye yardımcı olduğu(Naktiyok ve Kök, 2006) sonucuna ulaşıldığı görülmüştür.

\section{ARAŞTIRMA}

\subsection{Araştırmanın Amacı}

$\mathrm{Bu}$ araştırmanın amacı banka çalışanlarının iç girişimcilik düzeylerinin ve iç girişimciliğin çeşitli demografik değişkenlere göre farklılık gösterip göstermediğinin tespitine yöneliktir.

Hizmet sektöründe faaliyet gösteren banka çalışanları için müşterilerine daha yeni ve yaratıcı hizmet sunma gayreti hem kendilerine hem de bankalarına fayda sağlayacaktır. Bu noktada günümüz iş dünyasında iç girişimcilik kurum ve çalışanlar için vazgeçilmez bir unsur haline gelmiştir.

\subsection{Araştırmanın Sınırlılıkları}

Bu araştırma Balıkesir ilinde faaliyet gösteren ulusal bankalardaki çalışanlar üzerinde yapılmış olup, ülkemizin diğer bölgelerindeki banka çalışanlarının zaman ve imkanlar nedeniyle araştırmaya dahil edilememiş olması bu araştırmanın kısıtlarını oluşturmaktadır.

\subsection{Araştırmanın Örneklemi}

Balıkesir ilinde faaliyet gösteren ulusal bankalardaki çalışanlar bu araştırmanın ana kütlesini oluşturmaktadır. Anket uygulaması için kolayda örnekleme metodu seçilmiş ve uygulama yüz yüze yapılarak gerçekleştirilmiştir. Araştırma kapsamında araştırmaya katılmayı kabul eden 695 banka çalışanı ile görüşülmüş, eksik bilgi verilen 69 anket araştırmaya dahil edilmeyerek, 626 anket veri analizinde kullanılmıştır.

\subsection{Araştırmada Kullanılan Veri Toplama Araçları ve Verilerin Analizi}

Ankette, çeşitli araştırmacılardan yararlanılarak Durmaz (2011) tarafından geliştirilen 21 ifade ve 4 boyuttan oluşan iç girişimcilik ölçeği kullanılmıştır. Birinci bölümde, çalışanların yaş, medeni durum, cinsiyet, eğitim durumu, meslekteki toplam çalışma süresi, çalıştığı birim ve iş yerindeki pozisyonları gibi katılımcıların sosyo-demografik özelliklerini belirlemeye yönelik sorular yer alırken; anketin ikinci bölümünde iç girişimciliği ölçmeye yönelik 21 ifade yer almaktadır.

\section{ARAŞTIRMA BULGULARI VE VERILERIN ANALIZi}

\subsection{Demografik Faktörlere iliş̧kin Bulgular}

Tablo 1'de ankete katılan banka çalışanlarının demografik özelliklerini gösteren frekans dağılımları yer almaktadır. 
Tablo 1:Cevaplayıcıların Demografik Özelliklerine İlişkin Değerler

\begin{tabular}{|c|c|c|c|c|c|}
\hline Cinsiyet & Frekans & Yüzde & Öğrenim Düzeyi & Frekans & Yüzde \\
\hline Kadın & 252 & 40,3 & Lise & 53 & 8,5 \\
\hline Erkek & 374 & 59,7 & Ön Lisans & 101 & 16,1 \\
\hline Toplam & 626 & 100,0 & Lisans & 443 & 70,8 \\
\hline Pozisyon & Frekans & Yüzde & Master/Doktora & 29 & 4,6 \\
\hline Yetkili & 354 & 56,5 & Toplam & 626 & 100,0 \\
\hline Yönetmen & 186 & 29,7 & Gelir & Frekans & Yüzde \\
\hline $\begin{array}{l}\text { Müdür } \\
\text { Güvenlik }\end{array}$ & $\begin{array}{l}38 \\
48\end{array}$ & $\begin{array}{l}6,1 \\
7,7\end{array}$ & $\begin{array}{l}1.603-2.500 T L \\
2.501-3.500 T L\end{array}$ & $\begin{array}{l}181 \\
199\end{array}$ & $\begin{array}{l}28,9 \\
31,8\end{array}$ \\
\hline Toplam & 626 & 100,0 & 3.501-4.500TL & 156 & 24,9 \\
\hline Medeni Durum & Frekans & Yüzde & 4.501-TL ve üzeri & 90 & 14,4 \\
\hline$\overline{E v l i}$ & 425 & 67,9 & Toplam & 626 & 100,0 \\
\hline $\begin{array}{l}\text { Bekar } \\
\text { Toplam }\end{array}$ & $\begin{array}{l}201 \\
626\end{array}$ & $\begin{array}{l}32,1 \\
100,0\end{array}$ & & & \\
\hline
\end{tabular}

\begin{tabular}{lll}
\hline Çalıșma Süresi & Frekans & Yüzde \\
\hline $0-5$ Yıl & 188 & 30 \\
6-10 Yıl & 204 & 32,6 \\
11-15 Yıl & 131 & 20,9 \\
16-20 Yıl & 59 & 9,4 \\
Toplam & 626 & 100,0 \\
\hline Yaș & Frekans & Yüzde \\
\hline 25 ve Altı & 50 & 8 \\
$26-30$ & 185 & 29,6 \\
$31-35$ & 165 & 26,4 \\
$36-40$ & 117 & 18,7 \\
$41-45$ & 72 & 11,5 \\
46 ve Üzeri & 37 & 5,8 \\
Toplam & 626 & 100,0 \\
\hline
\end{tabular}

\subsection{Faktör Analizi, Güvenilirlik Testi ve Diğer Analizler}

Araştırmada kullanılan ölçeğin geçerliliği için açıklayıcı faktör analizi yapılmıştır. Analiz sonucunda 18 soru için iç girişimcilik ölçeğinin Cronbach's Alpha değeri ,812 olarak bulunmuştur. Ölçeğin boyutlarının güvenirliliğini belirlemek için her boyut için alfa katsayısı hesaplanmışır.Ölçeğin açıklanan toplam varyans değeri 57,825 olarak belirlenmiştir. Yapılan Açıklayııı Faktör Analizi (AFA) sonucunda, İç Girişimcilik ölçeğinin orijinal çalışma ile uyumlu olarak dört boyuttan oluştuğu görülmektedir.

Tablo 2: Açıklayıcı ve Doğrulayıcı Faktör Analizi Sonuçları

\begin{tabular}{|c|c|c|c|c|c|c|}
\hline \multirow{2}{*}{\multicolumn{2}{|c|}{ Değişkenler }} & \multicolumn{4}{|c|}{ Faktör Yükleri } & \multirow[t]{2}{*}{ Cronbach's Alfe } \\
\hline & & 1 & 2 & 3 & 4 & \\
\hline \multicolumn{7}{|c|}{ Faktör 1: Proaktiflik(PR) } \\
\hline PR3 & Kurumum, uzun vadeli planlamalarda çalışanlarının fikirlerinden yararlanır & ,786 & & & & \multirow{4}{*}{ - 837 } \\
\hline PR1 & Kurumum başka işletmeleri takip etmek yerine, daha önde olmaya çalışır & ,777 & & & & \\
\hline PR2 & Kurumum gelişmeleri takip etmek yerine kendisi gelişme üretir & ,777 & & & & \\
\hline PR4 & Kurumum, çalışanlarının yeni uygulamaları ve yenilik geliştirmelerini destekler & 755 & & & & \\
\hline \multicolumn{7}{|c|}{ Faktör 2: Risk Alma(RA) } \\
\hline RA6 & İçinde fırsat barındıran riskli işleri severim & & 750 & & & \multirow{5}{*}{,760 } \\
\hline RA4 & Önemli bir iş üzerindeyken köklü değişiklikler yapmaktan kaçınmam & & ,696 & & & \\
\hline RA2 & Belirsizlik altında karar verirken cesurumdur & & ,667 & & & \\
\hline RA1 & Görevimin başarısı için her türlü riski göze alırım & & ,658 & & & \\
\hline RA5 & Kurumum fırsatları değerlendirmek için,zaman, para,insan kaynağını etkin kullanır & &, 630 & & & \\
\hline \multicolumn{7}{|c|}{ Faktör 3: Özerklik(OZ) } \\
\hline $\mathbf{O Z 5}$ & Yenilik üretirken kurumumun standart prosedürlerini devre dışı bırakabilirim & & & ,764 & & \multirow{5}{*}{ 734 } \\
\hline OZ4 & Iş̧imle ilgili yenilik üretirken üstlerime danışmadan karar alabilirim & & & ,748 & & \\
\hline OZ3 & Bir görevde tek başıma görev almayı tercih ederim & & & ,697 & & \\
\hline OZ6 & Iş̧ hayatında başkalarının düşüncelerinden ziyade kendi düşündüklerim önemlidir & & & ,657 & & \\
\hline OZ1 & Kurumum yeni bir projede çalışanlarına özgür hareket alanı bırakır & & &, 559 & & \\
\hline \multicolumn{7}{|c|}{ Faktör 4: Yenilikçilik (YN) } \\
\hline YN3 & İşimle ilgili yenilik üretmek için çabalarım & & & & ,734 & \multirow{4}{*}{ 754, } \\
\hline YN2 & Kurumum, çalışanlarının yenilikçi olmalarını teşvik eder & & & &, 696 & \\
\hline YN1 & Yeni fikirlere açık birisiyim & & & & 687 & \\
\hline YN4 & Kurumum Ar-Ge faaliyetlerine, teknolojik gelişmelere ve yeniliğe önem verir & & & & 682 & \\
\hline \multicolumn{7}{|c|}{ Açıklanan toplam varyans : $57,825 \quad$ KMO örneklem yeterliliği ölçümü: ,805 , $\quad$ Kikare: 4083,252 P:,000 } \\
\hline
\end{tabular}

AFA sonucunda yeterli faktör yüklerini taşıyamayan 3 soru analizden çıkarılmıştır. Risk alma boyutu altında yer alan 3 nolu 'Belirsizlik ortamları, aynı zamanda atağa geçmek için bir firsat oluşturur', özerklik boyutu altında yer alan 2 nolu 'Kurumum yeni fikirlerin ortaya çıkması için bürokrasiyi azaltır' ve yenilikçilik boyutu altında yer alan 5 nolu 'Astlara yetki vermek yenilikçi fikirlerin çıkmasına yardımcı olur ' soruları analizin dışında tutulmuştur. 
Tablo 3: İç Girişicilik(Toplam) ve Boyutlarına Ait Ortalamalar

\begin{tabular}{|l|l|l|l|}
\hline & Gözlem & Ortalama & Std. Sapma \\
\hline Proaktiflik(PR) & 626 & 3,9696 &, 81993 \\
\hline Risk Alma (RA) & 626 & 3,7080 &, 80174 \\
\hline Özerklik(OZ) & 626 & 3,0863 &, 85811 \\
\hline Yenilikçilik(YN) & 626 & 4,2424 &, 67085 \\
\hline TOPLAM iç GiRişiMciLiK(IG) & 626 & 3,7122 &, 52741 \\
\hline
\end{tabular}

Araştırmamızın örneklemini oluşturan banka çalışanlarının (626 kişi) iç girişimcilik ortalamalarının yüksek sayılabilecek bir rakam olan 3,7122 olduğu tespit edilmiştir. Ayrıca iç girişimcilik boyutlarından en yüksek ortalamaya 4,2424 ile "yenilikçilik" boyutunun sahip olduğu görülmektedir. En düşük ortalama ise 3,0863 ile "özerklik" boyutuna aittir.

Tablo 4: İç Girişimcilik Boyutları ile Cinsiyet Değişkeni Arasındaki “t Testi”

\begin{tabular}{|l|l|l|l|l|l|l|}
\hline \multicolumn{2}{|c|}{ Cinsiyet } & (PR) & (RA) & (OZ) & (YN) & (IG) \\
\hline \multirow{3}{*}{ KADIN } & Ortalama & 3,8526 & 3,6072 & 3,0924 & 4,2311 & 3,6574 \\
\cline { 2 - 7 } & $\mathbf{N}$ & 251 & 251 & 251 & 251 & 251 \\
\cline { 2 - 7 } & Std. Sapma &, 85422 &, 82333 &, 86777 &, 65260 &, 54100 \\
\hline \multirow{3}{*}{ ERKEK K } & Ortalama & 4,0481 & 3,7759 & 3,0786 & 4,2533 & 3,7488 \\
\cline { 2 - 7 } & $\mathbf{N}$ & 374 & 374 & 374 & 374 & 374 \\
\cline { 2 - 7 } & Std. Sapma &, 78867 &, 78180 &, 85113 &, 68139 &, 51627 \\
\hline \multicolumn{2}{|c|}{$\mathbf{t}$} & $-2,938$ & $-2,590$ &, 197 &,- 407 & $-2,129$ \\
\hline \multicolumn{2}{|c|}{$\mathbf{d f}$} & 623 & 623 & 623 & 623 & 623 \\
\hline \multicolumn{2}{|l|}{$\mathbf{p}$} & $\mathbf{0 0 3 *}$ & $\mathbf{0 1 0} *$ &, 844 &, 684 &, $\mathbf{0 3 4 * *}$ \\
\hline
\end{tabular}

iç girişimcilik boyutları ile cinsiyet değişkeni arasında anlamlı bir farklılık olup olmadığı 't Testi' ile incelenmiş ve Proaktiflik, Risk alma boyutları ile toplam iç girişimciliğin cinsiyete göre anlamlı farklılık gösterdiği belirlenmiştir. Erkeklerin kadınlara göre proaktiflik, risk alma ve toplam iç girişimcilik ortalamalarının daha yüksek olduğu görülmektedir.

Tablo 5: Eğitim Değişkenine Göre İ̧̧ Girişimcilik Ortalamaları

\begin{tabular}{|l|l|l|l|l|}
\hline \multicolumn{2}{|c|}{} & N & Ortalama & Standart Sapma \\
\hline \multirow{4}{*}{ IG_Ort } & Lise & 53 & 3,8501 &, 44104 \\
\cline { 2 - 5 } & Ön Lisans & 101 & 3,6892 &, 51730 \\
\cline { 2 - 5 } & Lisans & 443 & 3,6886 &, 53573 \\
\cline { 2 - 5 } & Master & 26 & 3,8889 &, 54251 \\
\cline { 2 - 5 } & Doktora & 3 & 4,0000 &, 44096 \\
\cline { 2 - 5 } & Toplam & $\mathbf{6 2 6}$ & $\mathbf{3 , 7 1 2 2}$ & $\mathbf{, 5 2 7 4 1}$ \\
\hline
\end{tabular}

Araştırmamızda doktora eğitimine sahip örneklem sayısı az olmakla birlikte doktora eğitimine sahip banka çalışanları en yüksek iç girişimcilik ortalamasına sahiptir. Doktoralıları sırasıyla Master, Lise, Ön lisans ve Lisans mezunları takip etmektedir.

Tablo 6:Yaş Değişkenine Göre İç Girişimcilik Ortalamaları

\begin{tabular}{|l|l|l|l|l|}
\hline \multicolumn{2}{|c|}{} & N & Ortalama & Standart Sapma \\
\hline \multirow{5}{*}{ IG_Ort } & 25_ve Altı & 50 & 3,6922 &, 55456 \\
\cline { 2 - 5 } & $26-30$ & 185 & 3,6201 &, 53774 \\
\cline { 2 - 5 } & $31-35$ & 165 & 3,7114 &, 47116 \\
\cline { 2 - 5 } & $36-40$ & 117 & 3,7384 &, 52942 \\
\cline { 2 - 5 } & $41-45$ & 72 & 3,9082 &, 53256 \\
\cline { 2 - 5 } & 46_ve Üzeri & 37 & 3,7387 &, 57867 \\
\cline { 2 - 5 } & Toplam & $\mathbf{6 2 6}$ & $\mathbf{3 , 7 1 2 2}$ &, $\mathbf{5 2 7 4 1}$ \\
\hline
\end{tabular}

Yaş değişkenine göre iç girişimcilik ortalamalarına bakıldığında, 3,9082 ile 41-45 yaş aralığındaki banka çalışanlarının en yüksek ortalamaya sahip olduğu ve 3,6201 ile en düşük ortalamaya 26-30 yaş gurubu çalışanların sahip oldukları tespit edilmiştir. 


\section{SONUÇ}

Bu çalışma, banka çalışanlarının iç girişimcilik düzeylerinin ve iç girişimciliğin çeşitli demografik değişkenlere göre farklılık gösterip göstermediğinin tespitine yönelik yapılmıştır. Araştırma sonuçlarına göre cinsiyet değişkenine göre toplam iç girişimcilik ile proaktiflik ve risk alma boyutlarında anlamlı farklılıklar tespit edilmiş ve her üçü için erkeklerin daha yüksek ortalamaya sahip oldukları görülmüştür. Araştırmamız özelinde eğitim değişkenine göre iç girişimcilik değerlendirildiğinde doktora ve master eğitimine sahip banka çalışanlarının daha yüksek iç girişimcilik ortalamasına sahip olduğu belirlenmiştir.

Araştırmamızın örneklemini oluşturan banka çalışanlarının (626 kişi) iç girişimcilik ortalamalarının yüksek sayılabilecek bir rakam olan 3,7122 olduğu tespit edilmiştir. Ayrıca iç girişimcilik boyutlarından en yüksek ortalamaya 4,2424 ile "yenilikçilik" boyutunun sahip olduğu, en düşük ortalamanın ise 3,0863 ile "özerklik" boyutuna ait olduğu görülmektedir.

Araştırmamıza katılan banka çalışanları arasında iç girişimcilik ortalamasının 3,9082 ile 41-45 yaş aralığındaki grupta en yüksek seviyede olduğu görülmektedir. En düşük iç girişimcilik ortalaması ise 26-30 yaş aralığında tespit edilmiştir. Bu sonuç bankalarda iç girişimcilik kültürünün tam olarak oturtulmadığına işaret olarak yorumlanabilecektir.

Organizasyonlar büyüdükçe ve olgunlaştıkça hareket kabiliyetleri azalmakta, kararlar bürokratik duvarları aşamadığından geç alınmakta ve bu sonuç da beraberinde ataleti getirmektedir. Atalet ise örgütler için büyük dezavantajlar oluşturmakta ve hatta örgütün yaşamına kastetmektedir. Örgütlerin atalete düşmeleri yaşam döngülerinin olağan bir sonucu gibi görünse de, bu sonun geciktirilmesi yada ataletten çıkılması için bir çözüm de iç girişimcilikten geçmektedir. Bu sebeple iç girişimcilik konusunun örgüte kazandırdıklarının iyi anlaşılması ve örgütlerin bunu yaşatmak adına bir kültür geliştirmeleri ve çalışanların bunu içselleştirmeleri önem arz etmektedir.

Araştırmamız Balıkesir ilinde faaliyet gösteren bankalardaki çalışanlar üzerinde yapılmış olup, ülkemizin diğer bölgelerinde faaliyet gösteren banka çalışanları ya da farklı sektörlerde de benzer araştırmaların yapılması gelecekteki araştırmacılara önerilmektedir.

\section{KAYNAKLAR}

Augusto Felício, J., Rodrigues, R., Caldeirinha, V. R. (2012). The effect of intrapreneurship on corporate performance. Management Decision, 50(10), 1717-1738.

Antoncic, B., Hisrich, R. D. (2001). Intrapreneurship: construct refinement and cross-cultural validation. Journal of business venturing, 16(5), 495-527.

Ferreira, J. (2001). Corporate entrepreneurship: a strategic and structural perspective. New England Journal of Entrepreneurship, 4(2), 59.

Güler, E. B. B. (2012). İç girişimcilik: bir literatür taraması. Gümüşhane Üniversitesi Sosyal Bilimler Enstitüsü Dergisi, 3(6).

Hill, M. E. (2003). The development of an instrument to measure intrapreneurship: entrepreneurship within the corporate setting.

Heinonen, J., Korvela, K. (2003, September). How about measuring intrapreneurship. In Conference Proceedings of 33rd EISB (Entrepreneurship, Innovation and Small Business). Conference in Milan, Italy. 1-18

Kaya, N., Arkan, A. F. (2005). Örgütsel faktörlerin, şirket girişimciliğinin potansiyel sonuçlarina etkileri: bilgi teknolojileri ve iletişim sektöründe bir araştırma. İstanbul Üniversitesi İsletme Fakültesi İsletme İktisadı Enstitüsü Dergisi: Yönetim, 16(12), 7-16.

Monnavarian, A., Ashena, M. (2009). Intrapreneurship: the role of social capital-empirical evidence and proposal of a new model of intrapreneurship and its relationship with social capital. Business Strategy Series, 10(6), 383-399.

Naktiyok, A., Bayrak Kök, S. (2006). Çevresel faktörlerin iç girişimcilik üzerine etkileri. Afyon Kocatepe Üniversitesi, i.i.B.F. Dergisi Cilt:8, Sayı:2, 77-96

Parker, Simon. C. (2011). Intrapreneurship or entrepreneurship?. Journal of Business Venturing, 26(1), 19-34.

Pinchot III, G. (1985). Intrapreneuring: why you don't have to leave the corporation to become an entrepreneur.

Thornberry, N. (2001). Corporate entrepreneurship: antidote or oxymoron? European Management Journal, Cilt:19, Sayı:5, 526-533.

Zahra, S. A. (1991). Predictors and financial outcomes of corporate entrepreneurship: an exploratory study. Journal of business venturing, 6(4), 259-285. 